\title{
Clinical implementation of the hysteroscopic morcellator for removal of intrauterine myomas and polyps. A retrospective descriptive study
}

\author{
Tjalina Wibeke Oona Hamerlynck • Viviane Dietz • \\ Benedictus Christiaan Schoot
}

Received: 17 July 2010 / Accepted: 26 August 2010 / Published online: 21 September 2010

(C) The Author(s) 2010. This article is published with open access at Springerlink.com

\begin{abstract}
The aim of this study is to report our experience with a novel technique, the hysteroscopic morcellator (HM), for removal of intrauterine myomas and polyps. We performed a retrospective study on 315 women undergoing operative hysteroscopy with the HM in our university-affiliated teaching hospital. We collected data on installation and operating times, fluid deficit, peri- and postoperative complications. In 37 patients undergoing myomectomy with the HM, mean installation time was $8.7 \mathrm{~min}$, mean operating time, $18.2 \mathrm{~min}$, and median fluid deficit, $440 \mathrm{~mL}$. Three out of $37 \mathrm{HM}$ procedures were converted to resectoscopy, related to a type 2 myoma. In 278 patients, mean installation and operating times for polypectomy with the HM were $7.3 \mathrm{~min}$ and $6.6 \mathrm{~min}$, respectively. All procedures were uneventful. Implementation of the HM for removal of type 0 and 1 myomas $\leq 3 \mathrm{~cm}$, and removal of polyps appears safe and effective.
\end{abstract}

Keywords Operative hysteroscopy $\cdot$ Hysteroscopic morcellator Endometrial polyp $\cdot$ Submucous myoma

\section{Background}

The use of hysteroscopic mono- or bipolar instruments is considered the gold standard in circumstances where scissors are not successful for removal of intrauterine

Electronic supplementary material The online version of this article (doi:10.1007/s10397-010-0627-7) contains supplementary material, which is available to authorized users.

T. W. O. Hamerlynck $(\bowtie) \cdot$ V. Dietz $\cdot$ B. C. Schoot Department of Obstetrics and Gynecology, Catharina Hospital Eindhoven, PO Box 1350, 5602 ZA Eindhoven, The Netherlands e-mail: tjalina.hamerlynck@ugent.be lesions (e.g., myomas or polyps) [1,2]. The choice of a specific hysteroscopic instrument depends on the origin, location, as well as the size of the intrauterine lesion $[1,2]$. Recently, a novel device, the hysteroscopic morcellator (HM), became commercially available, using mechanical cutting to reduce the tumor into small chips and consequently evacuating these chips out of the uterine cavity by aspiration. The HM has been reported as an effective and safe new technique to remove intrauterine lesions [3]. Furthermore, it was reported that the HM is a safe and effective alternative to conventional resectoscopy in both experienced and inexperienced hands [4]. Results with the $\mathrm{HM}$ in clinical practice have hardly been documented [3, 4]. In this article, we present our retrospective data on the HM for removal of intrauterine myomas and polyps.

\section{Methods}

In our university-affiliated teaching hospital (Catharina Hospital, Eindhoven, the Netherlands), the HM was introduced in 2006 for hysteroscopic removal of intrauterine lesions. Up till that year, resectoscopy had been the standard procedure. We evaluated the introduction of the $\mathrm{HM}$ in retrospect.

Morcellation was performed with the HM (TRUCLEAR, Smith \& Nephew, Andover, USA; Fig. 1). The HM has a 4-mm blade, consisting of a rigid inner tube which rotates within an outer tube. The blade is inserted into an electrically powered control unit which connects to a handheld motor drive unit. A foot pedal activates the blade and regulates the direction of rotation of the internal blade tube. The direction can be oscillating or continuous, with the optimal number of rotations per minute being 750 or 1,100 , respectively. The rotary morcellator is recommended 


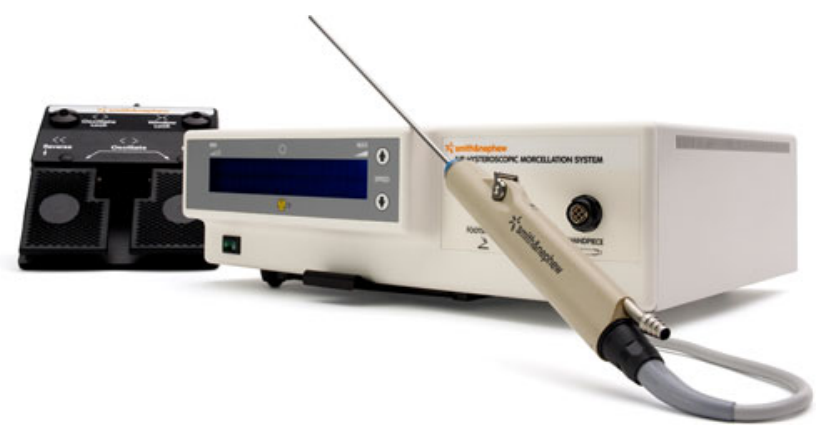

Fig. 1 The hysteroscopic morcellator

for polypectomy, and the reciprocating blade for myomectomy (Fig. 2).

The blade has a window opening at the end with cutting edges through which tissue is aspirated by means of a vacuum source. The vacuum source is connected to a regulator valve with a manometer. The optimal suction power connected to the inner tube of the HM blade is $200 \mathrm{mmHg}$. When the inner tube is not activated, the window opening is locked to prevent active suction of the distension liquid in order to avoid uterine cavity collapse. The removed tissue is discharged through the device, collected in a pouch, and made available for pathology analysis.

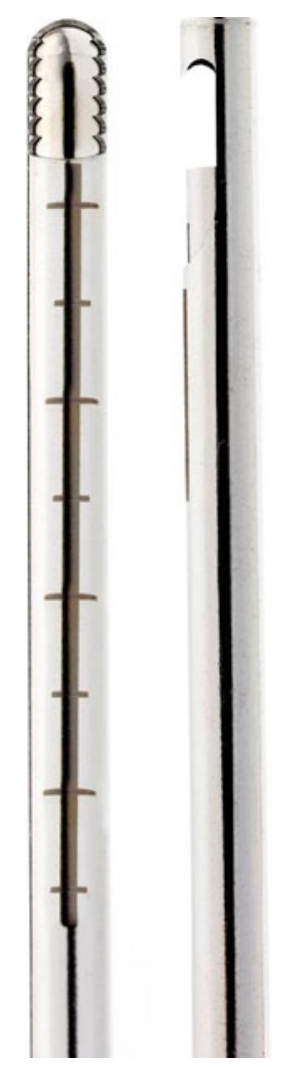

Fig. 2 The rotary and reciprocating blade of the HM
The blade of the HM was introduced into the uterine cavity through the working channel of a continuous flow 9-mm rigid hysteroscope with 0-degree optic (Smith \& Nephew, Andover, USA). After dilatation of the internal os of the uterine cervix with Hegar dilators, atraumatic insertion was accomplished with the use of an obturator in the outer sheath of the hysteroscope. The working channel also acts as the inflow channel and the hysteroscope contains a separate outflow channel. Continuous flow was used for optimal distension, irrigation, and visibility. The inflow is pressurized with a peristaltic pump (Smith \& Nephew, Andover, USA) with a maximum pressure setting of $120 \mathrm{mmHg}$ and a maximum flow setting of $700 \mathrm{~mL} / \mathrm{min}$, similar to standard resectoscopy. The outflow is passive. Normal saline was used for distension and irrigation of the uterine cavity. All fluid was collected from the passive outflow tubing of the hysteroscope as well as from the vacuum tubing connected to the inner blade, and both measured volumes were subtracted from the measured inflow volume resulting in the fluid deficit.

First, we retrospectively describe our results with the HM - using the reciprocating blade - for removal of type 0 and 1 myomas from 2006 until 2009. We collected information on time needed to install the equipment, operating time, fluid deficit, and peri- and postoperative complications from medical records. Conversion rates to resectoscopy are mentioned.

Secondly, we report our data for removal of intrauterine polyps with the HM - using the rotary blade - between 2006 and 2009. We collected data on installation and operating time, fluid deficit, peri- and postoperative complications, and conversion rates from medical records.

For both myomas and polyps, the diameter was measured by ultrasound preoperatively. Patients were hospitalized in daycare. Procedures were performed under spinal or general anesthesia, and data on type of anesthesia are given. All patients received antibiotic prophylaxis with a single dose of metronidazole $500 \mathrm{mg}$ and cefuroxime $1,500 \mathrm{mg}$. For all procedures, data on pathology analysis were available.

\section{Findings}

Myomas

Our results for removal of intrauterine myomas with the HM are summarized in Table 1. We performed this HM procedure in 37 patients aged 26 to 49 (median 45 years). The mean myoma diameter was $2.0 \mathrm{~cm}$. A type 0 myoma was seen in 23 patients (62\%), 11 patients had a type 1 myoma (30\%), and three patients (8\%) had a type 2 myoma. Since the HM can only be used for complete 
Table 1 Data on hysteroscopic myomectomy and polypectomy with the HM

\begin{tabular}{|c|c|c|c|c|c|c|c|c|c|}
\hline \multirow[t]{2}{*}{ Tissue } & \multirow[t]{2}{*}{$N$} & \multirow[t]{2}{*}{$\begin{array}{l}\text { Age } \\
{\left(\text { years }^{\mathrm{a}}\right.}^{\mathrm{a}}\end{array}$} & \multirow[t]{2}{*}{$\begin{array}{l}\text { Diameter of } \\
\text { tissue }(\mathrm{cm})^{b}\end{array}$} & \multirow[t]{2}{*}{$\begin{array}{l}\text { Installation } \\
\text { time }(\min )^{b}\end{array}$} & \multirow[t]{2}{*}{$\begin{array}{l}\text { Operating time } \\
(\mathrm{min})^{\mathrm{b}}\end{array}$} & \multirow[t]{2}{*}{$\begin{array}{l}\text { Fluid deficit } \\
(\mathrm{mL})^{\mathrm{a}}\end{array}$} & \multicolumn{3}{|c|}{$\begin{array}{l}\text { Type of } \\
\text { myoma }\end{array}$} \\
\hline & & & & & & & 0 & 1 & 2 \\
\hline Myoma & 37 & $45(26-49)$ & $2.0(0.4)$ & $8.7(1.4)$ & $18.2(4.1)$ & $440(100-890)$ & 23 & 11 & 3 \\
\hline Polyp & 278 & $47(23-81)$ & $2.4(0.7)$ & $7.3(2.5)$ & $6.6(3.3)$ & $40(0-300)$ & - & - & - \\
\hline
\end{tabular}

${ }^{\text {a }}$ Values are median (range)

${ }^{\mathrm{b}}$ Values are mean (SD)

the tissue fragments by the HM ensures a clear view and tissue is preserved for histological examination. In contrast, in resectoscopy, tissue fragments can block the hysteroscopic view and they need to be removed one by one, thus, making repeated in and out movements necessary, possibly causing uterine damage, and fragments might be lost.

We do acknowledge certain disadvantages of the HM. First, the inability to coagulate bleeding vessels encountered during surgery might be a disadvantage [5]. However, so far, no significant intraoperative or postoperative bleeding was documented [3]. In addition, our results show no evidence of significant bleeding during or after the HM procedure. Secondly, the HM cannot be used for the treatment of type 2 submucous fibroids [2]. Therefore, conversions to resectoscopy might occur when a type 2 myoma is misdiagnosed as a type 1 myoma preoperatively. Third, in case of larger myomas, the use of the HM can become quite time consuming. Fourth, in general, the cost of the disposables (blades and tubings) needed to perform a HM procedure is higher than that of the material needed for a hysteroscopic resection. Finally, regional or general anesthesia is mandatory for the HM procedure as it is necessary to dilate the cervix up to 8 or $9 \mathrm{~mm}$. In contrast, data on successful ambulant removal of polyps, sized 2 $4.5 \mathrm{~cm}$ [7-10], and submucous and partially intramural myomas, with a diameter up to $2 \mathrm{~cm}$ [7], with Versapoint (twizzle) have been published.

We report short installation and operating times for hysteroscopic myomectomy and polypectomy with the HM. Emanuel et al. report a mean operating time of $16.4 \mathrm{~min}$ for myomectomy and 8.7 min for polypectomy with the HM [3]. Comparing these data to other hysteroscopic techniques, the HM shows a marked reduction in the time needed to perform hysteroscopic myomectomy and polypectomy. Emanuel et al. reported a mean operating time of $42.2 \mathrm{~min}$ for hysteroscopic myomectomy and $30.9 \mathrm{~min}$ for polypectomy with the monopolar resectoscope [3]. Preutthipan et al. reported mean operating times ranging from $20.9 \mathrm{~min}$ to $31.9 \mathrm{~min}$ for polypectomy with grasping forceps, microscissors, electric probe, and resectoscope [11].

Unfortunately, data for our study were retrieved retrospectively, and in our center, no comparable control group was available for other hysteroscopic techniques. Prospective studies comparing the HM with, for example, monopolar

resectoscopy are needed to confirm the possible advantages of consequent gas embolism [6]. Furthermore, aspiration of 
the HM-such as the reduction of operating time-for removal of myomas and polyps. One should also retrieve more long-term follow-up data checking for persistence or recurrence of intrauterine myomas and polyps. Costeffectiveness of the HM also needs to be evaluated.

\section{Conclusion}

We conclude that in our experience, the HM is a fast, safe, and easy method for removal of both smaller type 0 and 1 myomas, as well as polyps. Prospective data are needed to confirm these findings.

Declaration of interest We report no conflict of interest.

Open Access This article is distributed under the terms of the Creative Commons Attribution Noncommercial License which permits any noncommercial use, distribution, and reproduction in any medium, provided the original author(s) and source are credited.

\section{References}

1. Gimpelson RJ (2000) Hysteroscopic treatment of the patient with intracavitary pathology (myomectomy/polypectomy). Obstet Gyn Clin N Am 27:327-337
2. Sardo ADS, Mazzon I, Bramante S, Bettocchi S, Bifulco G, Guida M, Nappi C (2008) Hysteroscopic myomectomy: a comprehensive review of surgical techniques. Hum Reprod Update 14:101-119

3. Emanuel MH, Wamsteker K (2005) The intra uterine morcellator: a new hysteroscopic operating technique to remove intrauterine polyps and myomas. J Min Invas Gynecol 12:62-66

4. van Dongen H, Emanuel MH, Wolterbeek R, Trimbos JB, Jansen FW (2008) Hysteroscopic morcellator for removal of intrauterine polyps and myomas: a randomized controlled pilot study among residents in training. J Min Invas Gynecol 15:466-471

5. Vilos GA, Abul-Rafea B (2005) New developments in ambulatory hysteroscopic surgery. Best Pract Res Clin Obstet Gynecol 19:727-742

6. Murakami T, Tamura M, Ozawa Y, Suzuki H, Terada Y, Okamura K (2005) Safe techniques in surgery for hysteroscopic myomectomy. J Obstet Gynaecol Re 31:216-223

7. Bettocchi S, Ceci O, Di Venere R, Pansini MV, Pellegrino A, Marello F, Nappi L (2002) Advanced operative office hysteroscopy without anaesthesia: analysis of 501 cases treated with a 5 Fr. bipolar electrode. Hum Reprod 17:2435-2438

8. Garuti G, Cellani F, Colonnelli M, Grossi F, Luerti M (2004) Outpatient hysteroscopic polypectomy in 237 patients: feasibility of a one-stop "see-and-treat" procedure. J Am Assoc Gynecol Laparosc 11:500-504

9. Garuti G, Centinaio G, Luerti M (2008) Outpatient hysteroscopic polypectomy in postmenopausal women: a comparison between mechanical and electrosurgical resection. J Minim Invas Gyn L 15:595-600

10. Litta P, Cosmi E, Saccardi C, Esposito C, Rui R, Ambrosini G (2008) Outpatient operative polypectomy using a $5 \mathrm{~mm}$ hysteroscope without anaesthesia and/or analgesia: advantages and limits. Eur J Obstet Gynecol Reprod Biol 139:210-214

11. Preutthipan S, Herabutya Y (2005) Hysteroscopic polypectomy in 240 premenopausal and postmenopausal women. Fertil Steril $83: 705-709$ 